\title{
Endoscopic 'antireflux' procedures: Not yet ready for prime time
}

\author{
Joseph Romagnuolo MD FRCPC MSc (Epid)
}

\begin{abstract}
J Romagnuolo. Endoscopic 'antireflux' procedures: Not yet ready for prime time. Can J Gastroenterol 2004;18(9):573-577.
\end{abstract}

Gastroesophageal reflux disease affects a significant portion of the North American population on a weekly and daily basis. Options, especially for erosive disease, involve long-term proton pump inhibitors or surgical fundoplication. More recently, a number of endoscopic antireflux techniques have been assessed. These fall into three broad categories: the Stretta (radiofrequency); endoscopic suturing and plication devices; and injectable bulking agents. In the present summary, the literature on these endoscopic techniques is critically reviewed, highlighting the unimpressive efficacy, potential and real complications, and the relevant methodological limitations of the studies. Although they are promising, it is clear that these procedures are still in a preliminary study phase and not ready for 'prime time' clinical use.

Key Words: Esophageal manometry; Gastroesophageal reflux; Lower esophageal sphincter; $\mathrm{pH}$; Therapeutic gastroscopy; Treatment

\section{Techniques antireflux endoscopiques : Pas tout à fait au point}

Le reflux gastro-œsophagien affecte une portion importante de la population nord-américaine sur une base hebdomadaire et même quotidienne. Surtout dans les cas de maladie érosive, les options thérapeutiques reposent sur l'utilisation prolongée d'inhibiteurs de la pompe à protons ou sur la fundoplication chirurgicale. Récemment, un certain nombre de techniques antireflux endoscopiques ont été évaluées. Ces techniques forment trois grandes catégories : Stretta (radiofréquence), suture et plication endoscopique et agents de volume injectables. Le présent sommaire passe en revue de façon critique la littérature sur ces techniques endoscopiques et présente la relative inefficacité, les complications potentielles et avérées et les limites méthodologiques de chacune. Bien qu'elles soient prometteuses, ces interventions n'en sont manifestement qu'à une phase préliminaire de leur mise au point et sont loin d'être prêtes à faire leur entrée dans la pratique clinique.
$\mathrm{G}$ astroesophageal reflux disease (GERD) affects 20\% of

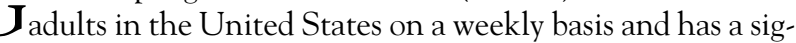
nificant effect on the quality of life for North Americans $(1,2)$. The pathophysiology involves an increase in transient lower esophageal sphincter relaxations, decreased lower esophageal sphincter (LES) pressure (intrinsic weakness and pharmacological weakness), mechanical factors such as hiatus hernia and obesity. Each component contributes to a different extent in any given patient (3). A minority of patients will have abnormally high gastric acid secretion (eg, Zollinger-Ellison syndrome). In addition to the widespread problem with symptoms in society, epidemiological data strongly suggest that longstanding untreated GERD predisposes to adenocarcinoma, likely through the development of Barrett's metaplasia $(4,5)$.

The subset of GERD patients who have erosive esophagitis have very poor healing rates with histamine-2 receptor antagonists, and many are unable to be maintained in remission even after healing with a proton pump inhibitor (PPI) (6). Data from the detailed healing and maintenance study by Klinkenberg-Knol et al (7) show that the relapse rate after cessation of PPI therapy is extremely high, and justifies virtually lifelong therapy in many of the patients presenting with erosive disease. Alternatives to the costs (8) and inconvenience of long-term acid suppression therapy in those with erosive esophagitis include laparoscopic or open fundoplication.

A review of the fundoplication literature is not the purpose of the present paper. However, a brief commentary is necessary to provide a frame of reference against which to compare the new technologies being discussed. Fundoplication is reported to improve quality of life $(9,10)$ and possibly Barrett's esophagus (11) and extraesophageal manifestations of reflux (12). There is reasonable intermediate- and long-term data to suggest that laparoscopic fundoplication is effective at healing and maintaining erosive esophagitis, eliminating medically refractory symptoms, and/or keeping patients off of PPIs for over three to five years $(9,13,14)$. Less impressive results were recently reported 10 years after open surgical fundoplication $(62 \%$ of patients remained medication-free) (15). The widespread use of laparoscopic fundoplication is limited by local expertise and the fact that it remains a surgical procedure requiring a general anesthetic. The median length of stay of such a procedure is one to two days (8) and it has a $10 \%$ to $15 \%$ conversion-to-open rate. Both short-term (20\% to $30 \%)$ and long-term (5\% to $15 \%)$ dysphagia and gas-bloat syndrome can occur as a complication in a minority of patients (16). Within the Canadian health care system setting, laparoscopic Nissen fundoplication appears to be less costly than medical therapy when PPI use of more than three years is anticipated (8).

Division of Gastroenterology and Department of Community Health Sciences, University of Calgary Medical Clinic, Calgary, Alberta.

Correspondence: Dr Joseph Romagnuolo, Medical University of South Carolina, 96 Jonathan Lucas Street, CSB Suite 210

PO Box 250327, Charleston, South Carolina 29425, USA. Telephone 843-792-2301, fax 843-792-8395, e-mail romagnuo@musc.edu Received for publication January 9, 2004. Accepted May 27, 2004 
Given the marked costs of long-term medical therapy and the morbidity in a small proportion of patients who undergo surgery for reflux, there has been growing interest in a number of outpatient endoscopic options for treating reflux. There are three broad categories of endoscopic antireflux procedures:

- The Stretta procedure: Inducing changes (inflammation and fibrosis) in the LES and surrounding tissue with radiofrequency energy;

- Endoscopic suturing and plication: suturing of folds of the lower esophagus and upper stomach; and

- Injection bulking procedures: LES augmentation by injection of a biocompatible material.

Some methodological concerns common to the reported studies are highlighted, followed by a review of each of the endoscopic antireflux techniques in turn.

\section{COMMON METHODOLOGICAL CONCERNS}

Endoscopic studies are often difficult to blind unless there is a sham endoscopy arm. While subjective end points, such as improved quality of life and symptom reduction, are important, these are often too prone to bias to be used alone for research purposes. Objective end points can circumvent some of this bias and become critical when blinding is not used in the study design. This is especially true for early work on new technologies, for which the mechanism of the anticipated reduction in symptoms has not been well worked out. For GERD, such objective end points exist and are readily available $(24 \mathrm{~h}$ esophageal $\mathrm{pH}$ monitoring and LES manometry). It is therefore disappointing that despite a nonrandomized and nonblinded study design being chosen for many of the reported studies, subjective end points were typically selected as the primary outcomes and objective end points were either relegated to secondary outcomes or not reported at all.

Another criticism that is common to many of the reported studies is that the populations studied may not allow generalizations of the results to the GERD population at large. In general, a new technology should be studied among a population most willing to undertake the risk of an unproven option, especially if it involves more risk than standard care (ie, proton pump inhibition). The obvious choice would be either those subjects whose symptoms are refractory to standard therapy and/or those who are not candidates for standard surgical therapy (eg, substantial comorbidities). Patients with severe symptoms or erosive esophagitis are more likely to require long-term medical therapy and bear its costs and inconveniences, and are therefore more likely to be willing to undergo a more invasive procedure that is perceived to have the potential for cure. Unfortunately, many of the studies have specifically excluded some of these patients.

\section{THE STRETTA PROCEDURE}

The Stretta procedure (Curon Medical Inc, USA) induces changes (inflammation and fibrosis) in the LES and surrounding tissue using radiofrequency energy delivered via a probe fitted with four $22 \mathrm{G}$ nickel-titanium needle electrodes protruding radially into the lower esophageal wall from sheaths around a centering balloon, while the mucosa is cooled with water irrigation, using a temperature-controlled generator system. The probe is passed blindly through the mouth after the distance from the incisors to the squamocolumnar junction has been measured at endoscopy. To target the LES, two sets of treatments are applied every $0.5 \mathrm{~cm}$ from $2 \mathrm{~cm}$ above the squamocolumnar junction to $1.5 \mathrm{~cm}$ below the junction, rotating the probe $45^{\circ}$ at each level, to create a total of 15 to 25 lesion sets. The balloon is inflated before each treatment application and the balloon is deflated and reinflated after rotating the catheter. The procedure time is approximately $50 \mathrm{~min}$ to 60 min $(17,18)$. Fever, chest pain, dysphagia, aspiration, perforation and death have been reported as complications $(18-20)$.

\section{Nonrandomized trials of the Stretta procedure}

There are two studies published in Gastrointestinal Endoscopy in 2001 and 2002, both authored by Triadafilopoulos et al $(17,18)$ and sponsored by the manufacturer, Curon Medical Inc (USA). The second study (18) had the longer follow-up (12 months) and consisted of 118 patients. Seventy per cent of those patients did not have any esophagitis, and at baseline, 12\% required $\mathrm{H}_{2}$-blockers alone. Most patients were under the age of 50 years, and patients with large hiatus hernias were excluded.

Although GERD health-related quality of life (GERDHRQL) improved, the changes in more objective end points were disappointing. The mean per cent of time spent below a $\mathrm{pH}$ of 4 during $24 \mathrm{~h} \mathrm{pH}$ monitoring improved from a mean of $10.2 \%$ (at baseline) to a mean of $6.4 \%$ (at six months), but this was still abnormal (normal less than 4\%). On average, the LES pressure was actually lower (weaker) by $2.4 \mathrm{mmHg}$ at six months than at baseline. However, even if it had significantly increased, the lower end of the interquartile range for the LES pressure was already within normal limits before treatment began in the population studied $(17,18)$.

These unimpressive results were obtained at the cost of a $1 \mathrm{~h}$ procedure time, and complications in $8.6 \%$ of patients, including fever, chest pain (one patient required hospitalization for investigations) and transient dysphagia (1\%) (18). The investigators also disclosed that they held an equity position in the sponsoring company (18).

\section{Sham-controlled randomized trial}

A multicentred trial enrolling 64 patients and featuring a sham-treatment control arm design, was recently published by Corley et al (19). The median per cent of time below $\mathrm{pH} 4$, on $24 \mathrm{~h} \mathrm{pH}$ monitoring, changed from $9.5 \%$ to $9.9 \%$ at six months in the treatment group and from $9.9 \%$ to $10.7 \%$ in the control group. Although objective acid exposure appeared to worsen in both the sham and the active treatment, a 3.5\% improvement was reported to occur in a subgroup analysis of 'responders'. The results reached statistical significance (2.4\% drop in acid exposure; $\mathrm{P}=0.01$ ) only when patients who crossed over in the sham arm were added to the treatment group (a post hoc analysis). Interestingly, the authors did observe a decrease in symptoms from baseline to six months follow-up despite the lack of objective clinically important improvement in acid exposure.

\section{Summary}

The Stretta procedure appears to improve symptoms in patients with mild GERD. However, this occurs without normalizing lower esophageal acid exposure or correcting abnormally low sphincter pressure, so it is unclear what the Stretta 
procedure actually does. One postulated mechanism of action is that the procedure reduces the frequency of transient LES relaxations. Another suggestion is that the radiofrequency energy may cause local afferent nerve damage, leading to altered sensitivity of the esophagus to reflux rather than prevention of reflux. If that is the case, one could question the overall safety of the Stretta procedure, as this apparent 'numbing' could prevent patients from tailoring their medications to their symptoms and untreated reflux may have adverse longterm consequences (eg, Barrett's esophagus or cancer), despite its beneficial effect on quality of life in the short term. The procedure time is very lengthy and a number of perforations and deaths have been reported to the US Food and Drug Administration with the Stretta procedure (especially in the first six months of use) (20). Given the lack of convincing evidence for effectiveness to counterbalance the immediate risks and unknown long-term effects, its use does not seem to be supported at this time, despite the 'positive' sham-controlled study.

\section{ENDOSCOPIC SUTURING AND/OR PLICATION}

These procedures involve an endoscope, a device that sucks up a fold of mucosa through which a needle carrying a suture is pushed, and a knot pusher and suture cutter. The procedure often requires an overtube (20 $\mathrm{mm}$ outer diameter), takes about $60 \mathrm{~min}$ to $70 \mathrm{~min}$ to complete and requires general anesthesia in $10 \%$ to $20 \%$ of patients (21). Complications of the procedure include dysphagia, perforation and overtube-related trauma and hypoxia (21).

\section{Nonrandomized studies}

Apart from the initial pilot data, there are now two published nonrandomized case series $(21,22)$. The first study, involving 34 study subjects, was sponsored by one of the manufacturers (Bard Interventional Products, USA). Unfortunately, those patients with severe or refractory disease were excluded from involvement in the study. As a result, $81 \%$ of the patients included in this study had a normal endoscopy, or erythema alone at enrollment.

Reduced regurgitation and improvement in two of eight quality of life measures were reported, but it is unclear if the improvement was clinically meaningful and there did not seem to be a correction for multiple hypothesis testing. LES pressures were reported to have increased from $16.1 \mathrm{mmHg}$ to $20.6 \mathrm{mmHg}$ at six months follow-up following the plication procedure (normal range, $10 \mathrm{mmHg}$ to $30 \mathrm{mmHg}$ ), but the significance of this is uncertain given that baseline pressures were normal. The daily esophageal acid exposure (percentage of time with $\mathrm{pH}$ less than 4) dropped from $9.6 \%$ at baseline to $9.3 \%$ at three months and to $8.5 \%$ at six months (normal, less than $4 \%)$. However, 11 patients $(32 \%)$ required a repeat procedure. Moreover, of the 34 patients in the initial study cohort, almost one-third either dropped out $(n=10)$ or had incomplete data $(n=3)$, creating potential for selection bias. Complications included a patient with esophageal microperforation with mediastinal air on computed tomography requiring hospitalization. Oxygen desaturation occurred in four patients and two of the procedures were performed under monitored anesthesia.

A second, nonrandomized series by Velanovich et al (22) is also available, comparing endoscopic (Endocinch) gastroplication with age- and sex-matched patients undergoing laparoscopic fundoplication. There was no difference between the endoscopic and surgical groups with regard to patient satisfaction, symptoms or GERD-HRQL scores. Similar to many other studies assessing the new endoscopic antireflux technologies, symptoms and patient satisfaction alone were chosen as primary end points of success.

\section{Summary}

Suturing and plication procedures have a significant learning curve for operating the suturing device, and the procedure time is long. A minor objective reduction in esophageal acid exposure and a reduction in regurgitation have been demonstrated with this procedure. So far, there is insufficient data available to support the introduction of this technique into clinical practice.

\section{INJECTION OR BULKING PROCEDURES}

Technically, these are probably the easiest of the available endoscopic antireflux procedures to perform and a growing number of injection/bulking techniques are being reported in the literature $(23,24)$. A sclerotherapy injection needle and a gastroscope is all that is required, with either fluoroscopy or endoscopic ultrasound to document the submucosal location of the injected substance. One to six injections are used. The typical procedure time is $20 \mathrm{~min}$ to $30 \mathrm{~min}$. Apart from the Gatekeeper (Medtronic, USA) procedure (25), the substance injected is not removable. Therefore, most of the techniques involve long-term or permanent placement of a hypoallergenic inert foreign substance into the esophageal wall.

Plexiglas microspheres: Polymethylmethacrylate

One of the choices for injection therapy involves plexiglas microspheres: polymethylmethacrylate (PMMA). The plexiglas microspheres are $100 \mu \mathrm{m}$ in size and have a smooth surface, proposed to hinder phagocytosis and migration. The injectable microspheres are diluted $1: 3$ in a heated $3.5 \%$ bovine spongiform encephalitis-free gelatin solution.

An uncontrolled, unblinded study of this technique by Feretis et al (23) recruited 10 patients. Only half had evidence of esophagitis. Although seven of the 10 patients were off medication after PMMA implantation, the acid exposure time was still abnormal (7.2\% of time less than $\mathrm{pH}$ of 4 versus $25 \%$ at baseline). Three of the five patients with esophagitis had successful endoscopic healing. Chest pain requiring oral analgesics occurred in two patients as well as dysphagia and gas bloat syndrome lasting for three weeks in one patient. Antibodies to the gelatin did not develop.

\section{Enteryx: Ethylene vinyl alcohol}

The second injectable therapy involves a biopolymer (ethylene vinyl alcohol [Enteryx, Boston Scientific, USA]). A multicentred study reported by Devière et al (24) recruited only 15 patients with reflux over 12 months at two major European centres. This very slow recruitment pattern raises some concerns regarding external validity, patient selection and patient acceptability.

The LES pressure increased from $12.2 \mathrm{mmHg}$ to $16.7 \mathrm{mmHg}$, which was still abnormal (normal, $10 \mathrm{mmHg}$ to $30 \mathrm{mmHg}$ ), at a six-month median follow up (24). Subjective (and biasprone) reflux scores were improved but $27 \%$ of patients had to go back on a PPI in the short term. The effect of the procedure on quantitative esophageal acid exposure was not reported. Just over one-half of the patients had mild retrosternal chest pain requiring oral analgesics for one to three days following 
the procedure. One patient developed two weeks of mild dysphagia.

Two additional published reports on the Enteryx technology present six- and 12-month follow-up results, respectively, of an uncontrolled, prospective, multicentred study $(26,27)$. Eighty-five patients with abnormal esophageal acid exposure and daily PPI therapy for more than three months were recruited. The average age was 50 years and patients with large hernias and esophagitis with a Savary-Miller grade greater than two were excluded. Two-thirds of the recruited subjects had no esophagitis at all, and 25\% had Savary-Miller grade 1 (nonerosive) esophagitis.

Normalization of acid exposure occurred in 39\% (26). Despite a significant improvement, the mean per cent of time spent with a pH less than 4 on $24 \mathrm{~h}$ monitoring was still abnormal post-treatment. Symptoms and quality of life scores improved, but esophagitis did not improve in 56\% of patients, and actually became worse in $27 \%$. Mild or moderate dysphagia was noted in $20 \%$ of patients. One-half of these affected patients had symptoms for two to 12 weeks and one required dilation. Chest pain was reported in $92 \%$ of patients and was moderate to severe in $55 \%$ of these; in $17 \%$ the chest pain lasted longer than two weeks. Nineteen patients (22\%) underwent a second 'implantation' procedure.

\section{Summary}

Injection and bulking procedures are fairly easy to perform, requiring only a relatively short procedure time with a relatively low procedure-related complication rate. Although improvement is demonstrated in both subjective and objective measures, the benefit appears to be significant in less than one-half of the patients and effectiveness in healing esophagitis appears to be poor. The most significant theoretical concern with these techniques is the unknown long-term effects of having an injected bioimplant in or around the LES. Both materials have been used for other medical indications: Enteryx has been used for embolization of arterial venous malformations (28) while the PMMA have been used in dental prostheses (23). It remains unclear whether this unknown, albeit small, risk is outweighed by the benefit of a minor improvement in reflux, without necessarily an improvement in esophagitis, in the face of widely available virtually side effect-free, more effective, medical options.

\section{OTHER ENDOSCOPIC ANTIREFLUX PROCEDURES}

A number of other devices are under development, but clinical studies researching the uses of these devices have not been published in manuscript form. The same degree of critical appraisal of their facility, efficacy and safety is therefore not possible. The following (three) therapies have either only been studied in animal models (29), or have only been presented in abstract form $(25,30)$.

Other plication devices are also under development, including a full-thickness endoscopic plication system (NDO Surgical Inc, USA), which consists of a reusable plicator instrument, a single-use cartridge containing a suture-based implant, and a specially designed endoscopic tissue retractor. The procedure is done under direct endoscopic vision, with the gastroscope retroflexed after passing through a channel in the plicator (which is placed in the stomach over a guidewire). This effectively eliminates the need for and risks of an overtube and repeated esophageal intubations. The only fully published paper on this device is an animal model (29).

An endoscopically placed esophageal ring with a tubular valve extending the esophagus to the cardia, called the gastroesophageal antireflux device (GARD), has also been described in abstract form (30). The Gatekeeper (Medtronic, USA) is another injectable therapy that involves submucosal injection of an expandable, and possibly removable, hydro gel prosthesis, but this procedure has only been described in abstract form and a significant proportion of the implants are suspected to pass into the lumen spontaneously (25).

\section{CONCLUSION}

All of these endoscopic 'antireflux' procedures are clearly in preliminary stages of study. Whether any of them actually prevent gastroesophageal reflux remains unclear, and many of the techniques are time consuming (over an hour in some cases, with or without general anaesthesia) and involve significant infrequent risks. The risk-to-benefit ratio seems most favourable for the injection therapies, but they remain to be tested in randomized controlled clinical trials. The evidence used to support the introduction of these techniques into clinical practice is far less than that which would be required for the introduction of a new pharmacological therapy. This makes their widespread dissemination into clinical practice, which seems to be happening in the United States and elsewhere, particularly disturbing (31). When safe and effective options are already available, 'promising' endoscopic therapies should not be available for 'prime time' clinical use until the 'promising' becomes 'proven' in well-designed clinical trials. The use of these techniques should remain restricted to research protocols.

\section{REFERENCES}

1. Locke GR, 3rd, Talley NJ, Fett SL, Zinsmeister AR, Melton LJ, 3rd. Prevalence and clinical spectrum of gastroesophageal reflux: A population-based study in Olmsted County, Minnesota. Gastroenterology 1997;112:1448-56.

2. Dimenas E, Glise H, Hallerback B, Hernqvist H, Svedlund J, Wiklund I. Quality of life in patients with upper gastrointestinal symptoms. An improved evaluation of treatment regimens? Scand J Gastroenterol 1993;28:681-7.

3. Long JD, Orlando RC. Anatomy, histology, embryology, and developmental anomalies of the esophagus.

In: Feldman M, Friedman LS, Sleisenger MH, eds. Feldman, Sleisenger \& Fordtran's Gastrointestinal and Liver Disease: Pathophysiology, Diagnosis, Management, 7th edn. Vol 1. Philadelphia: Elsevier Science; 2002:549-671.

4. Lagergren J, Bergstrom R, Lindgren A, Nyren O. Symptomatic gastroesophageal reflux as a risk factor for esophageal adenocarcinoma. N Engl J Med 1999;340:825-831.

5. Shaheen N, Ransohoff DF. Gastroesophageal reflux, barrett esophagus, and esophageal cancer: Scientific review. JAMA 2002;287:1972-81.

6. Beck IT, Champion MC, Lemire S, et al. The second Canadian consensus conference on the management of patients with gastroesophageal reflux disease. Can J Gastroenterol 1997;11(Suppl B):7B-20B.

7. Klinkenberg-Knol EC, Festen HP, Jansen JB, et al. Long-term treatment with omeprazole for refractory reflux esophagitis: Efficacy and safety. Ann Intern Med 1994;121:161-7.

8. Romagnuolo J, Meier MA, Sadowski DC. Medical or surgical therapy for erosive reflux esophagitis: Cost-utility analysis using a Markov model. Ann Surg 2002;236:191-202. 
9. Oelschlager BK, Barreca M, Chang L, Oleynikov D, Pellegrini CA. Clinical and pathologic response of Barrett's esophagus to laparoscopic antireflux surgery. Ann Surg 2003;238:458-66.

10. Perdikis G, Hinder RA, Lund RJ, Raiser F, Katada N. Laparoscopic Nissen fundoplication: Where do we stand? Surg Laparosc Endosc 1997;7:17-21.

11. Heikkinen TJ, Haukipuro K, Bringman S, Ramel S, Sorasto A, Hulkko A. Comparison of laparoscopic and open Nissen fundoplication 2 years after operation. A prospective randomized trial. Surg Endosc 2000;14:1019-23.

12. Spechler SJ, Lee E, Ahnen D, et al. Long-term outcome of medical and surgical therapies for gastroesophageal reflux disease: Follow-up of a randomized controlled trial. JAMA 2001;285:2331-8.

13. Granderath FA, Kamolz T, Schweiger UM, Pointner R. Quality of life, surgical outcome, and patient satisfaction three years after laparoscopic Nissen fundoplication. World J Surg 2002;26:1234-8.

14. Kamolz T, Granderath F, Pointner R. Laparoscopic antireflux surgery: Disease-related quality of life assessment before and after surgery in GERD patients with and without Barrett's esophagus. Surg Endosc 2003;17:880-5.

15. Oelschlager BK, Eubanks TR, Oleynikov D, Pope C, Pellegrini CA. Symptomatic and physiologic outcomes after operative treatment for extraesophageal reflux. Surg Endosc 2002;16:1032-6.

16. Wills VL, Hunt DR. Dysphagia after antireflux surgery. Br J Surg 2001;88:486-99.

17. Triadafilopoulos G, Dibaise JK, Nostrant TT, et al. Radiofrequency energy delivery to the gastroesophageal junction for the treatment of GERD. Gastrointest Endosc 2001;53:407-15.

18. Triadafilopoulos G, DiBaise JK, Nostrant TT, et al. The Stretta procedure for the treatment of GERD: 6 and 12 month follow-up of the US open label trial. Gastrointest Endosc 2002;55:149-56.

19. Corley DA, Katz P, Wo JM, et al. Improvement in gastroesophageal symptoms after radiofrequency energy: A randomized, shamcontrolled trial. Gastroenterology 2003;125: 668-76.

20. Fleischer DE. The Stretta procedure: Technique optimization and complication rates. Gastrointest Endosc 2002;55:256 (Abst).
21. Filipi CJ, Lehman GA, Rothstein RI, et al. Transoral, flexible endoscopic suturing for treatment of GERD: A multicenter trial.[comment]. Gastrointest Endosc 2001;53:416-22.

22. Velanovich V, Ben-Menachem T, Goel S. Case-control comparison of endoscopic gastroplication with laparoscopic fundoplication in the management of gastroesophageal reflux disease: Early symptomatic outcomes. Surg Laparosc Endosc Percutan Tech 2002;12:219-23.

23. Feretis C, Benakis P, Dimopoulos C, et al. Endoscopic implantation of Plexiglas (PMMA) microspheres for the treatment of GERD. Gastrointest Endosc 2001;53:423-6.

24. Deviere J, Pastorelli A, Louis H, et al. Endoscopic implantation of a biopolymer in the lower esophageal sphincter for gastroesophageal reflux: A pilot study. Gastrointest Endosc 2002;55:335-41.

25. Lehman GA, Watkins JL, Hieston K, et al. Endoscopic gastroesophageal reflux disease (GERD) therapy with Gatekeeper system. Initiation of a multicenter prospective randomized trial. Gastrointest Endosc 2002;55:261 (Abst).

26. Johnson DA, Ganz R, Aisenberg J, et al. Endoscopic implantation of enteryx for treatment of GERD: 12-month results of a prospective, multicenter trial. Am J Gastroenterol 2003;98:1921-30.

27. Johnson DA, Ganz R, Aisenberg J, et al. Endoscopic, deep mural implantation of Enteryx for the treatment of GERD: 6-month follow-up of a multicenter trial. Am J Gastroenterol 2003;98:250-8.

28. Terada T, Nakamura Y, Nakai K, et al. Embolization of arteriovenous malformations with peripheral aneurysms using ethylene vinyl alcohol copolymer. Report of three cases. J Neurosurg 1991;75:655-60.

29. Chuttani R, Kozarek R, Critchlow J, et al. A novel endoscopic fullthickness plicator for treatment of GERD: An animal model study. Gastrointest Endosc 2002;56:116-22.

30. Godin N. The GARD (Gastro-esophageal anti-reflux device) for GERD: An office procedure. Preliminary report. Gastrointest Endosc 2002;55:261 (Abst).

31. Hogan WJ. Endoscopic treatment modalities for GERD: Technologic score or scare? Gastrointest Endosc 2001;53:541-5. 


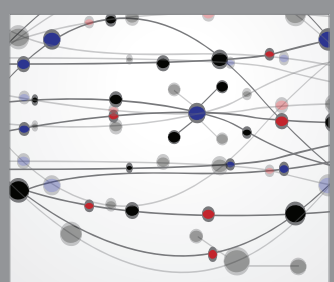

The Scientific World Journal
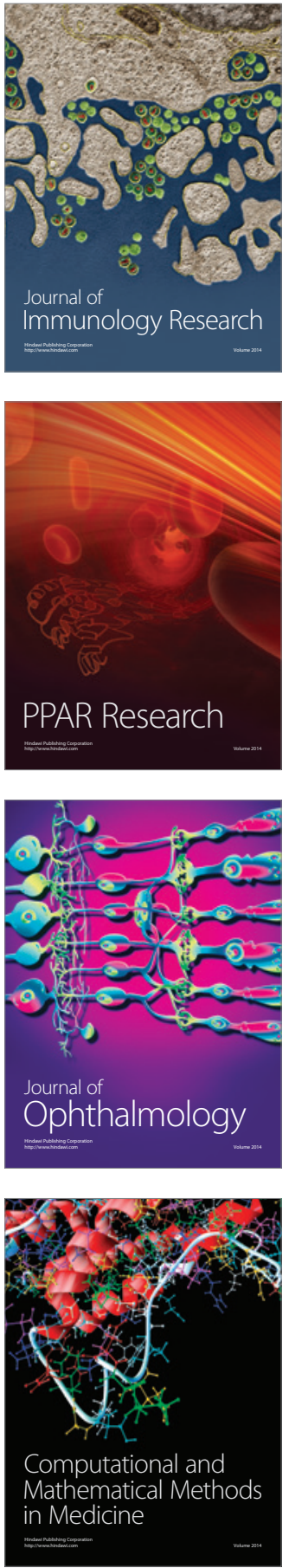

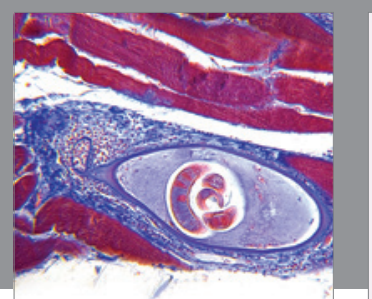

Gastroenterology Research and Practice

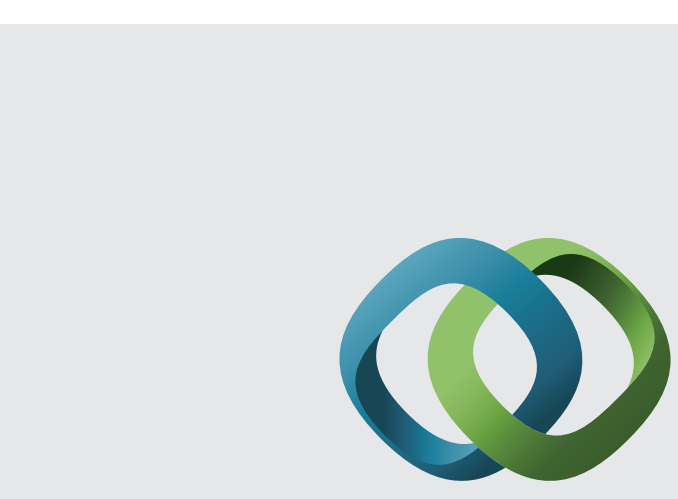

\section{Hindawi}

Submit your manuscripts at

http://www.hindawi.com
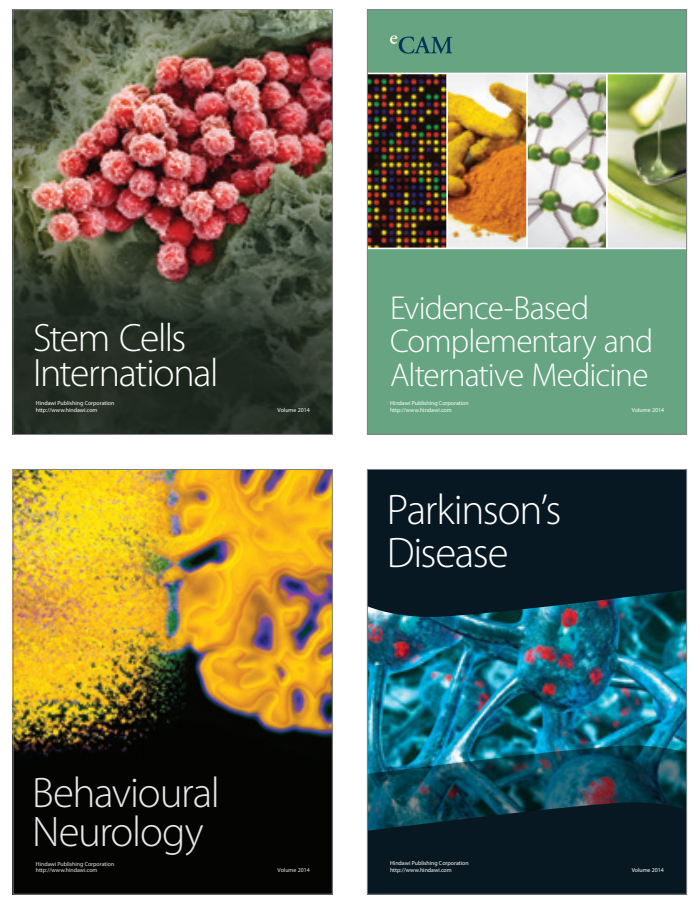
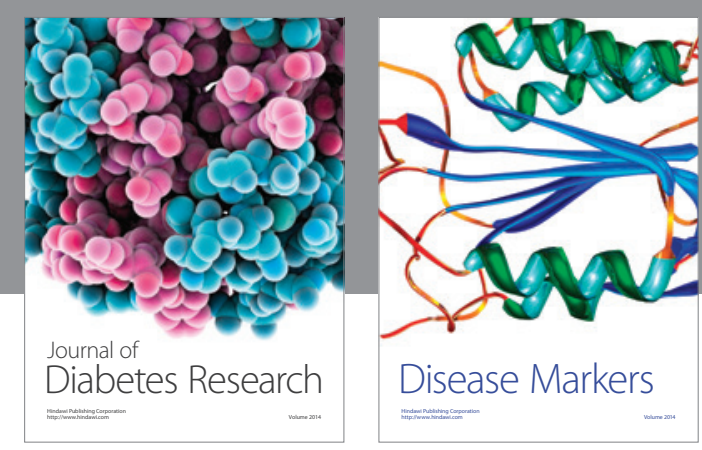

Disease Markers
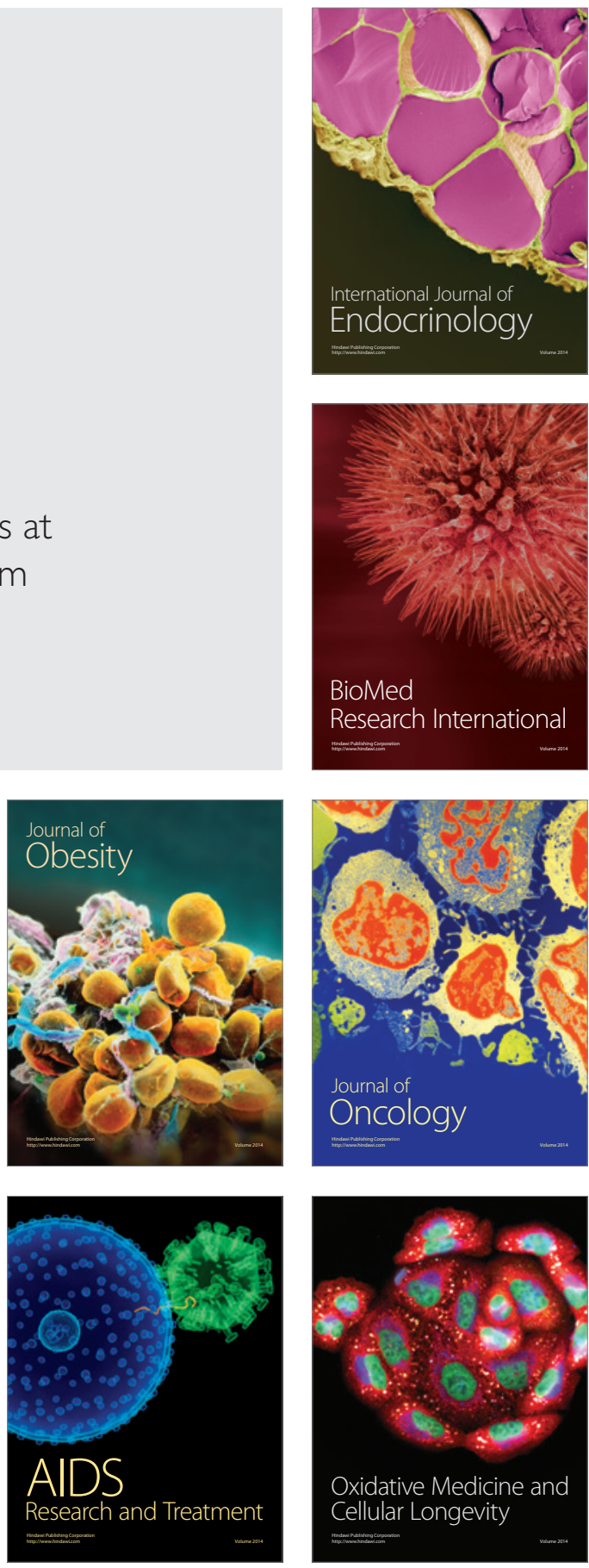